\title{
Dialectical Relationship between Translation Theory and Practice
}

\author{
Siyu Zou
}

(Nanchang Institute of Technology, Nanchang, China, 330099)

\author{
Keywords: Translation theory and practice; Dialectical; Harmony thought
}

\begin{abstract}
Translation theory has actually formed a relatively complete dialectical system. This paper recognizes the important role of the translator and the translation reader in the process of translation. Therefore, through the different attitudes from predecessors, taking the translator and the translation reader are included in the scope of translation theory. In other words, translation theory involves several important factors in the translation process, including the origin, translator, reader and translation. On the one hand, the original text as the starting point for translation must be respected, so the translation should be faithful to the original. On the other hand, because $100 \%$ faithfulness is not operational and the translation is for translation service of the readers, so the translation should be consistent with the reader's reading habits when keeping the faithfulness. This paper mainly elaborates the dialectical attitudes in the discussion of translation theory, and then puts forward some suggestions on the future research direction.
\end{abstract}

\section{Introduction}

The relationship between translation theory and practice is like discussing the relationship between any other thing, should first recognize that the two things are contradictory and unified dialectical relations, but the key lies in how to analyze and really unit the contradiction. This analysis must, of course, proceed from the reality of the matter, and it must avoid subjective and one-sided, although we are clear that absolute objectivity and comprehensiveness are impossible to achieve. But we must advocate seeking truth from facts, which is a matter of course. Seeking the theory and practice truthfully, first of all, we should see that they are intrinsically closely related, united, and that there is equally unthinkable of no theoretical practice and unprotected theory(the latter is obvious): who's translation of the activities without any theoretical guidance, from your choice of translated materials to the implementation of translation methods, the grasp of translation standards; you can say that there is no principle, there is no rational thinking analysis, you can not deny this, that is, to admit that there is no practice absolutely departure from the theory. The question lies only in the guidance of what kind of theory: it is a good theory or a bad theory, it is a profound theory or superficial theory, and even all kinds of faked "theory". The level of any real theory is self-evident, both the highest and most abstract theory is inextricably linked to the underlying theory and the fundamental practice, without doubt. Therefore the key is: the study of translation should not be afraid to rise to abstract philosophy, and never stop in abstract talk, in particular, must focus on making the proper abstract theory reasonably go through the appropriate intermediate links (often numerous and complex) until Specific translation methods, and effectively guide the practice of translation. This paper explores the principles and strategies of literary translation in China, and provides a translation strategy and method for literary translation.

\section{Harmony theory and harmony translation theory}

Harmony theory based on the profound Chinese traditional culture and culture, this paper explores the problem of translation theory with traditional Chinese language. It hopes to raise people's understanding of translation process and attribute wholly, and to solve the concrete translation problem in reality, the specific translation of the phenomenon in history, provides a new way and perspective. This section will trace harmony translation, and explore the meaning of harmony translation.

As we all know, in the translation of the standard discussion, there has been a the dual 
phenomenon of the original as one end and the recipient for the other end. In fact, when things appear in the normal method, their position is often existing the place between the binary, can be called "the third state." This is a relatively stable state that is largely in line with the requirements of the parties based on coordination and balance. In this state, the relationship between the various related factors is harmonious. Translation standards are looking for such a state. "The third state" embodies a "executive" philosophy. Ancient Greek Aristotle argues that all human behavior is excessive, less and moderately three states, the first two states are the characteristics of evil, only the third is the virtue of virtue, moral standards, such as brave stay in law cowardly and reckless, so it is virtue.

In the process of discussing the five main parts of "meaning", "honesty", "heart", "spirit" and "fitness", the author also puts forward a comprehensive and concrete request for the translator's cultivation. Therein, honesty mainly discusses the ethics question of translators, heart mainly discusses the translator 's cognitive metaphysics, and meaning mainly discusses the translator' $\mathrm{s}$ knowledge reserve and expression skills. "spirit" mainly discusses the translator 's aesthetic accomplishment and artistic creation. "fitness" mainly explains the translator 's social responsibility and the related problems of the realm.

\section{Dialectical Relations in Translation}

The most central question of linguistic translation research is how to establish a reciprocal relationship between source language and translated text, and equivalence is the core concept. Contemporary translation theory use semiotics, informatics, sociology, especially the new fruits of linguistics has made clearly description on the translation of the concept of 'equivalence', a variety of description has a common point - 'Functional equivalence', that is, the original type is different, the reader object is different, the different translation purposes, translation requirements are different, so the translation method is also different. Therefore, the 'reciprocal relationship' of the translation is relative, rather than absolute, you can not use the opinionated point of view to look at the 'reciprocal conditions'.

In addition to the theoretical introduction and demonstration of the concept of translation equivalence, but also from the theoretical level to learn the practical level. In this paper, the definition and supplement of the traditional grammar of the attributive clause are modified and supplemented, and the division of the restrictive and non - restrictive attributive clause is put forward. In terms of content and form, they are not absolute. The meaning of the attributive clause in the sentence, in addition to the content of the attributive, can also express the compound sentence and the contents of various adverbial clauses. In view of the central role of meaning in context, it is concluded that translation should first pay attention to the equivalence.

Example 1: And here I was, thrust directly into a country, Nationalist China, which was a completely repressive society and which fitted all the criteria of the fascist state we were supposed to be fighting .-- Ibid

And here I was, thrust directly into a country, Nationalist China, which was a completely repressive society and which fitted all the criteria of the fascist state we were supposed to be fighting .-- Ibid

Translation analysis: the original translation is hard to be understood, what's more, It leaves erroneous impression on readers. This completely misinterpreted the original intention. Because, on the contrary, when the negotiations were held in Chongqing, the United States was making great efforts to assist the Kuomintang fascist China.

\section{Translation Practice}

Translation are closely related to culture, therefore, how to deal with the cultural factors in the text has become an inevitable problem, especially for the source language culture have great difference with target language culture. Any translator knows that the sender of the information on the real world is different with the recipient of the information, there is no need to have a correspondence 
between the two sides. It is very the issue how to deal with cultural differences in the translation, the translation sectors have different viewpoint. According to their own practical experience, it is proposed that the language and cultural factors should be dealt with separately in the translation, the definition of literal translation and free translation should be limited to the scope of language form, the definition of alienation and naturalization should be limited to the scope of cultural content, neglect Ideological issues, only the discussion on the methodology, and redefine the above four concepts the following literal translation (literal translation): the methods of the expression of the language, in the scope of the target language allowed, basically follow the source language expression and faithful to the original meaning.

Free translation: the forms of language of the translation, fully follow the norms of the target language regardless of the source language expression, but loyal to the original meaning.

Alienation: in the translation, retain the cultural concepts and values of the source language, in particular, to retain the original metaphor, image and national, local color and so on.

Domestication: in the translation, to grasp the cultural concepts and values of the source language, replaced by with the cultural concepts and values the target language, in particular, the original metaphor, image and national, local color with the corresponding target language to replace.

Example 2: literal translation + alienation translation: translation retain the expression form of the source language, but also retain the cultural content of the source language.

Is cloning technology resulting the sword of Damocles to human beings?

Is the cloning technology increasingly becoming the handle of the human body on the head of the Damocles sword, all the time threatening our safety?

Example 3: literal translation + naturalization of the translation: the translation retain the form of expression the source language, but using the metaphor and the image of the targeted language to replace the original metaphor and image.

Forever hidden by a thick veil of dust and gas, the center of our Milky Way Galaxy can not be seen in visible light, the kind of light that our eyes see.

\section{Summary}

There is a complementary and mutually reinforcing relationship between harmony translation and contemporary western translation theory, rather than simple competition and substitution. We must systematically study the Western modern translation theory, take its essence, abandon its dross, adopt the dialectical attitude of "useism", accept the doubt and create the translation theory system which is suitable for our country's national conditions and Chinese language and culture translation business in China. This article treat the theory of harmony translation theory as the subject support, focusing on the embodied principle of harmony and translation from Guo Jianzhong harmony translation behavior, cultural principles, harmony and ethical principles of translation.

Project Funding: Humanities and Social Sciences in Jiangxi (No. YY162008)

\section{Reference}

[1] Zhang J J. Reconsideration of Nida: The theory and practice of translation [J]. Overseas English, 2015.

[2] Schwimmer M. Beyond theory and practice: to an ethics of translation [J]. 2017: 1-11.

[3] Institute M, University W M. Medieval Translation Theory and Practice I [J]. 2015.

[4] Zhu Y, Wang J. Corpus-based Translation Teaching: Theory and Practice [J]. Journal of North China University of Technology, 2015.

[5] Wei J. A Moodle-based Model for Teaching Written Translation Theory and Practice [J]. 2015, $5(5)$.

[6] Jiménez E A. Francisco Ayala and his professional approach to translation theory and practice [J]. Trans Revista De Traductología, 2015: págs. 195-209. 
[7] Rodrigues C C. Leal, Alice. Is the Glass Half Empty or Half Full, Reflections on Translation Theory and Practice in Brazil [J]. Cadernos De Traduçao, 2015, 35 (1): págs. 285-290.

[8] Fan X. On Value of He Lin's Theory and Practice of Translation to Chinese Translation Theory and Translation History [J]. Journal of Yibin University, 2015.

[9] Petersen M. Translation and quality management: Some implications for the theory, practice and teaching of translation [J]. Philosophical Explorations, 2017.

[10]Pym A. Translation Changes Everything: Theory and Practice [J]. The European Legacy, 2015, 20 (7): 1-2.

[11]Ratiu D. A-Translation - From Theory to Practice and Back [J]. Oncogene, 2017, 28 Suppl 1 (31): S38-S45.

[12] Shi C L. On the Theory Innovation and its Practice of Translation Textbook Compilation [J]. Journal of Baoji University of Arts \& Sciences, 2016. 